\title{
Parcerias e práticas sexuais de jovens homossexuais no Rio de J aneiro
}

\author{
Sexual partners and practices of young \\ homosexuals in Rio de J aneiro
}

Luís Felipe Rios 1,2

\footnotetext{
${ }^{1}$ Associação Brasileira Interdisciplinar de AIDS. Rua da Candelária 79 10 o andar, Rio de Janeiro, $R J$ 20091-020, Brasil.

2 Instituto de Medicina Social, Universidade do Estado do Rio de Janeiro. Rua São Francisco Xavier 524, Rio de Janeiro, $R J$ 20550-900, Brasil. fipo@bol.com.br
}

\begin{abstract}
This article focuses on the organization of the erotic lives of young men who engage in homosexual practices. The reflections presented here are based on ethnographic research including observation in places of homosociability and interviews with young men in Rio de Janeiro reporting homosexual practices. By presenting erotic scenes pertaining to a homoerotic circuit and recording the sexual trajectories of young men engaging in homosexual practices, the article seeks to identify the implications of the observed erotic scripts and sex-partner patterns for the sexual health of these individuals. The text calls special attention to reports concerning the emergence of different forms of erotic interaction in childhood, as well as cross-age and crossgenerational partnerships that extend into adulthood, with a growing trend toward seeking younger partners as the young men themselves grow older. The article suggests that such phenomena require a more in-depth understanding, since they have serious implications for planning sexual health measures for young men (and boys) who engage in homosexual practices.
\end{abstract}

Key words Male Homosexuality; Sex Behavior; Sexuality

Resumo Este artigo aborda aspectos da organização das vidas eróticas de homens jovens com práticas homossexuais. As reflexões apresentadas são embasadas em pesquisa etnográfica, que envolveu observações em espaços de homossociabilidade e entrevistas com jovens com práticas homossexuais do Rio de Janeiro. Por meio da apresentação de cenas eróticas próprias a um circuito homoerótico e pelo resgate das trajetórias sexuais de jovens com práticas homossexuais, este artigo busca apontar implicações dos roteiros eróticos e padrões de parcerias sexuais identificados para a saúde sexual desses mesmos jovens. O texto chama especial atenção para relatos sobre o surgimento de interações eróticas na infância, em parcerias interetárias e intergeracionais que se prolongam até a idade adulta, em uma crescente tendência a ir se invertendo (busca por parceiros mais novos em termos etários). O artigo sugere que tais fenômenos necessitam ser mais bem entendidos por possuírem sérias implicações para o planejamento de ações em saúde sexual para jovens (e crianças) com práticas homossexuais.

Palavras-chave Homossexualidade Masculina; Comportamento Sexual; Sexualidade 


\section{A presentação}

Neste artigo, busco refletir sobre alguns aspectos da organização das vidas eróticas de homens jovens com práticas homossexuais. As reflexões que apresento são embasadas em pesquisa etnográfica realizada entre adeptos do candomblé (Rios, 2001), e em pesquisa-ação realizada no âmbito de um trabalho de prevenção ao HIV/AIDS na Associação Brasileira Interdisciplinar de AIDS (ABIA) (Almeida et al., 2002)

No âmbito da referida pesquisa etnográfica, e para ter um contraponto para os dados e reflexões sobre a organização da sexualidade dos jovens com práticas homossexuais adeptos do candomblé, também foram realizadas observações em espaços de homossociabilidade fora das "casas de santo" e entrevistas com jovens com práticas homossexuais que não pertencem ao candomblé. Os dados aqui trabalhados são fruto, sobretudo, desse segmento investigado. A pesquisa seguiu as recomendações das Normas de Pesquisa Envolvendo Seres Humanos (Conselho Federal de Medicina, 1996), sendo submetida e aprovada pelo Comitê de Ética do Instituto de Medicina Social da Universidade do Estado do Rio de Janeiro.

Inicio este artigo reconstituindo e apresentando cenas eróticas próprias ao circuito homoerótico do Centro do Rio de Janeiro. Após essa parte mais descritiva, analiso as implicações dos roteiros eróticos (Paiva, 2000; Simon \& Gagnon, 1999), e padrões de parcerias sexuais identificados para a saúde sexual dos jovens com práticas homossexuais. Especialmente me chamaram a atenção as referências ao surgimento do erótico na infância, em interações interetárias e intergeracionais, padrões que possuem sérias implicações quando se quer pensar em chaves e subsídios para ações em saúde sexual mais afinadas com a pluralidade de contextos e vivências dos jovens (e crianças) com práticas homossexuais.

\section{Fábio - o sujeito coletivo}

Como recurso para a apresentação dos dados, recorro ao que chamo de sujeito coletivo. Criei um personagem ficcional, que poderia ser qualquer um dos rapazes com os quais tenho convivido nas minhas pesquisas ou ações educativas - ainda que nenhum deles, pois Fábio tem uma história que é só sua. Na construção de Fábio, seguindo o processo de construção das subjetividades como acontecem no mundo real, marquei-o por inserções de classe, de gê- nero, raciais, etárias, instrucionais, marcadores e padrões de beleza etc. Inserções que determinam as trajetórias de vida das pessoas e suscetibilidades a diferentes agravos sociais, como apontei em outro trabalho (Rios, 2002b).

De certa forma, Fábio, em diversos dos eventos que passarei a narrar, estará como que "incorporado" por algum dos homens com quem interagi no decurso da pesquisa - ou sendo "dirigido" por mim por meio de scripts (Simon \& Gagnon, 1999), que apreendi dos fatos que me foram narrados e das interações que observei. O leitor pode reencontrar essas múltiplas "entidades" com as quais Fábio terá “atuado" em alguns dos textos produzidos anteriormente, como Rios $(1997,2002 b)$ e Almeida et al. (2002), ou em interações e sujeitos descritos por outros autores, como Parker $(1991,2002)$ e Terto Jr. (1989).

Assim, se a minha experiência etnográfica foi suficiente para que eu chegasse às estruturas que orientam os eventos (Sahlins, 1990), quero crer que mesmo os fatos ficcionais são passíveis de ser reais - ou ainda, do mesmo modo como sugere Fry (1983), em relação à criação dos personagens Amaro e Aleixo por Adolfo Caminha no romance Bom-crioulo, as situações que Fábio representa, se não são verdadeiras, são verossímeis.

Fábio, desde 14 ou 15 anos, iniciou-se no circuito por que transitaremos descobrindo os diferentes lugares onde a sexualidade que "não ousa se dizer" encontra espaços para a sua realização. Hoje, aos 19 anos, ele é perito nas artes da "pegação" (paquera) e conhece todos os "buracos" e "inferninhos" do Centro e arredores.

Suas primeiras experiências sexuais datam ainda da infância. Ele lembra que, entre 5 e 6 anos, brincava e realizava explorações de eroticidade com os amigos e amigas da vizinhança e da escola. Algumas vezes, eles eram surpreendidos por um adulto ou irmão mais velho que os ameaçava e/ou os castigava física e/ou moralmente pelos atos que praticavam.

Aos 7 anos, deu-se a sua primeira vivência de sexo penetrativo com um colega, que, na época, tinha 14 anos. $\mathrm{O}$ amigo recomenda que não conte para ninguém o que faziam, pois tudo aquilo era da ordem do proibido - seria um segredo dos dois. O certo é que essa recomendação era desnecessária, pois o caráter de pecado e anormalidade das práticas que realizavam já haviam sido introjetados pelas práticas repressivas dos pais, dos professores etc. Aos 13 anos, introduziu outros coleguinhas menores nas mesmas práticas, além de "transar" (ter sexo) com homens mais velhos do que ele. Sempre teve muito prazer com o sexo, e isso o fez 
suplantar, desde cedo, a proibição e os argumentos contrários dos adultos.

Do ponto de vista de identidade sexual, só na época em que descobriu o circuito referido é que veio a se reconhecer como homossexual. Hoje, com 19 anos, Fábio não é alto nem baixo, nem é gordo nem é magro, também não é fisiculturista. Tem cabelos e olhos escuros, mas de pele clara. Ainda que não possua os exaltados atrativos contemporâneos de beleza, faz o tipo mediano, que “agrada a maioria": não é negro, não tem o cabelo pixaim, não é gordo, não é peludo. Também não é "afeminado" (utilização de marcadores do feminino hegemônico para compor performances de gênero). Assim, além de ter sua homossexualidade invisibilizada aos olhos do machismo e heterossexismo dominante, também transita muito bem no meio gay.

\section{Circuito do desejo}

O Centro da cidade do Rio de Janeiro. Ficarei circunscrito a um circuito muito conhecido pelos homens com práticas homossexuais - Campo de Santana e Central do Brasil, Via Ápia e Aterro do Flamengo, Cinelândia, Lapa, Avenida Mem de Sá e Rua Gomes Freire etc. Conforme Parker (2002), por seu grande movimento e sua relativa mistura de classes sociais, o Centro é um dos principais locais da vida gay no Rio de Janeiro.

Sexta-feira, primeira parada, Lapa, por volta das 23 horas. Para começar a noite, nada melhor do que uma cerveja em uma das barraquinhas que se amontoam na calçada que divide as duas vias de trânsito. Dali, Fábio pode observar o movimento, as pessoas chegando, passando. Os sentidos já estão alerta, pode calhar de cruzar o olhar, se não for com o "príncipe encantado" - que "todo" homem sonha um dia encontrar - pelo menos com um rapaz "gostoso" e "bom de cama" que "lhe dê muito prazer naquela noite". De preferência, que tenha o dinheiro para pagar as cervejas, o "churrasquinho de gato" e, sobretudo, o motel, caso a interação resulte em sexo. Vale lembrar que Fábio apenas estuda, iniciou um curso universitário, que os pais se esforçam em pagar na esperança de que o filho tenha um futuro melhor. Mas a noite está só começando, e encontrar o tal príncipe logo de cara nem sempre é fácil - ainda que seja um daqueles que "se transforma em sapo” aos primeiros raios da manhã ou após o orgasmo.

O seu point predileto é o Congado (nome fictício), que só abre às sextas; uma mistura de bar e dancing. Não é um lugar explicitamente "gay", mas a freqüência, pode-se dizer, é majoritariamente de homens. Também é possível afirmar que o homoerotismo "transpira junto com o suor". Fábio curte o local pelo que chama de "ecletismo". Quando toca funk, não há como negar, é tanta gente a se espremer ali que ou se "sarra” ou se é "sarrado", "não tem machão certo!”. Os “heterossexuais convictos” que se retirem, caso se sintam incomodados.

A “sarração" é caracterizada como o ato de esfregar-se, de "roçar" as partes erógenas em busca da excitação sexual; é entendida como um ato relacional, em que duas ou mais pessoas podem estar envolvidas.

No Congado, as cadeiras balançam, e as mãos correm. Para quem gosta de ser "sarrado" nas nádegas, é só ir se chegando para trás; quem tem outra preferência erótica, vai se chegando para frente e pode usar da genitália (escondida dentro da calça - ainda que já “agitada” pelo clima de sensualidade e erotização das músicas e dos corpos em movimentação) ou das mãos para "roçar" quem está na frente. Isso tudo acontece com muito tato, ou seja, checando por uma série de códigos as preferências eróticas do outro (se este responde positivamente, com olhares de aquiescência, aproximação, sorriso etc., ou negativamente, com cara feia, afastamento, pedido de licença - assim, a pessoa se desculpa e culpa a multidão). Mas, volto a lembrar, é necessário que seja tudo na discrição. Sem chamar muita atenção para o que está se passando dos dorsos para baixo!

No Congado, contribuem para a excitação de Fábio o jogo entre implícito e explícito e a suposta e discreta quebra dos tabus sexuais em um espaço supostamente heterossexual. Além disso, a excitação coletiva, quase orgiástica, mas sem a nudez dos genitais (e das nádegas).

Fábio, por não encontrar alguém interessante naquele espaço e como estava muito a fim de uma interação sexual "mais quente", foi, como de costume, até o Aterro - dez minutos de caminhada. O melhor horário para se chegar àquele local, um parque público, é entre 3 e 4 horas. Nesse horário, os guardas estão menos vigilantes, e isso permite que se fique mais relaxado. As pessoas estão saindo dos bares, boates e festas e vão chegando. Há também os que madrugam em busca de prazer sexual, e aquele é o lugar mais certo e mais barato para encontrá-lo.

As pessoas procuram os lugares mais ensombrados para parar e mostrar o pênis (os que têm preferências por interações sexuais em que sejam os penetradores, na boca ou no ânus). Há os que preferem se destacar; assim, ao arrumar alguém, não precisam dar espaço para uma interação grupal. Alguns preferem 
não ficar muito distantes dos outros, até porque não dispensam a potencialidade da excitação de observar as interações sexuais alheias. Podem até, quando determinados sinais são acionados, se aproximar, e o sexo grupal pode se formar. Há, ainda, os que ficam passeando de uma árvore a outra, sempre seguindo o caminho das sombras, para não chamar a atenção dos policiais.

Fábio parou sob a sombra de uma grande árvore e começou a se masturbar. Alguns passos adiante, outros rapazes, homens de meia idade e idosos também se masturbavam ou observavam os outros se masturbando. Às vezes, até que a masturbação individual dê passagem à coletiva, demora um pouco. A masturbação mútua pode resultar também em sexo oral (dual ou coletivo). No Aterro, como nas interações no Congado, a discursividade oral é mínima; são gestos, toques e olhares que sinalizam os sentidos, as vontades, os desejos e as práticas.

É comum, enquanto as pessoas se abraçam, enquanto os mamilos são sugados, as mãos trabalharem e os dedos verificarem se o parceiro gosta de ser penetrado. Um mesmo homem pode ser penetrado por vários, um após outro. Nesse tipo de interação erótica, é bastante comum o compartilhamento de "camisinhas": sem trocar o preservativo, um mesmo sujeito penetrar vários homens. Em geral, o uso do preservativo se restringe ao sexo anal, raramente é usado no sexo oral. Ainda no sexo anal, há sempre alguém transando sem ele.

Na verdade, não terei condições de descrever todos os tipos de interações que se formam em locais como o Aterro. Uma composição das que descrevi acima, porém, será recorrente. Quero assinalar, entretanto, que prevalece o clima de consentimento e respeito pelas disponibilidades alheias para as práticas. Se alguém não está gostando de um tipo de prática ou da tentativa de envolvimento de alguém que não se deseja, isso é sinalizado. Se o(s) parceiro(s) insiste (m), quem se sente incomodado procura outro lugar e/ou outra(s) pessoa(s).

Fábio está exausto da noite, dos "flertes", "sarros" e "transas". Segue, então, para casa, onde encontrará o "sono dos justos" e sonhará com o seu programa para o sábado: talvez uma visita ao clube Estrela da Noite (nome fictício), ainda nas imediações da Lapa.

Mudando a cena, os roteiros interpessoais que orientam as interações (Simon \& Gagnon, 1999), também mudam. No Estrela da Noite, o foco, bem mais que no Congado e, sobretudo, que no Aterro, é o da busca pelo contato verbal, ainda que também culmine no intercurso sexual.
Quando Fábio está à procura de "relacionamento", evita flertar com rapazes mais jovens. Em geral seus olhares se dirigem para homens mais velhos (em torno de dez anos). O Estrela da Noite é um dos lugares onde está buscando o seu "príncipe", que, entre outros requisitos, deve poder "bancá-lo" (assumir os custos do parceiro). Assim, um homem com dez anos a mais deve estar no lugar onde o próprio Fábio quer estar daqui a dez anos: estabilizado financeiramente.

Isso não quer dizer que, se algum rapaz mais jovem "lhe der mole", ele não permita a aproximação e não passe para os "sarros" ou para a "transa". De fato, isso ocorre muitas vezes, mas o que seus olhos buscam, sobretudo em espaços como esse, não é apenas alguém para "ficar" por uma noite - pelo menos até saturar o seu limite de cerveja.

Em suas escolhas, Fábio rapidamente analisa o vestuário e tipo físico, tentando encontrar indicativos de classe - não basta ser mais velho, tem de ser estabelecido. E, de tanto procurar, ele viu um rapaz interessante: camiseta básica, sapato de uma marca acessível às classes médias, calça jeans, em torno de 30 anos: o seu tipo ideal.

No Estrela da Noite, o contato nunca deve começar por toques, como no Congado, e o grau de exigência para permitir que um flerte ou "cantada" se transforme em interação corporal é bem maior. A discursividade oral é bem mais valorizada e nem sempre uma aproximação, ainda que desejada, culmina em sexo.

Após um ritual de aproximação - que envolve o entrecruzamento dos olhares e a aproximação verbal -, é a vez de uma conversa “em pé de orelha”. Carlos é o nome do novo personagem. Entabulada a aproximação, ainda sem contatos corporais, eles buscam um local mais apropriado para conversar, o que leva à "sarração".

As mãos trabalham, Fábio e Carlos se exploram mutuamente. Além do prazer imediato proporcionado pelos toques, é sempre bom saber a preferência erótica do provável parceiro "na cama” para que não haja mal-entendidos, pelo menos uma idéia quanto à preferência sexual - se o outro é "ativo/penetrativo" ou "passivo/receptivo", ou se isso não interessa a ele. Quando as posições são iguais e consideradas de modo fixo, fica difícil levar o relacionamento adiante, ainda que seja um relacionamento de uma única noite.

Fábio arrisca e passa a mão nas nádegas de Carlos que não se incomoda. Ao contrário, gosta - um aceno de que a passividade, se não é a preferência de Carlos, pelo menos não lhe é um "problema”. Fábio reforça as carícias e, já bas- 
tante excitado, enfia a mão por dentro das calças e da cueca do parceiro, descendo nádegas abaixo. Carlos “explode” de prazer. Ele propõe ao ouvido de Fábio que vão para outro lugar e sugere um motel perto dali. Fábio explica que o seu dinheiro acabou, só está com o da passagem. Carlos diz que não há problema, não tem muito dinheiro, mas dá para pagar o quarto.

Sobre o que aconteceu entre "as quatro paredes", deixo para as imaginações dos leitores. Pode auxiliar toda a gama de práticas que elenquei acima e as dicas que dei sobre os dois personagens. Só assegurarei que eles usaram preservativo nesse primeiro encontro. Talvez, se a relação se tornar duradoura, entre o terceiro e o sexto mês, eles abandonarão os preservativos, como prova de amor e de crença na fidelidade do outro.

\section{Roteiros da eroticidade}

No circuito gay descrito, o erótico, ainda que se articule com as normas de sexualidade (Parker, 1991; Rios, 2002a; Rubin, 1998), e negocie com as hierarquias de passividade/atividade do gênero (Parker, 1991; Rios, 2002a), orienta de forma preponderante a vida sexual dos homens que fazem sexo com homens (HSH). No sistema erótico, como descreve Parker (1991), a "norma" é a busca pelos prazeres que os corpos podem oferecer, ainda que, e sobretudo, às custas das quebras das regras dos outros dois sistemas - sistema de gênero e de sexualidade.

No âmbito do sistema erótico, e com base nas minhas observações, identifiquei quatro ordens que se entrecruzam na organização das práticas. Essas ordens, ainda que muitas vezes constituam no espaço social coletivo lugares específicos para as suas realizações, em verdade devem ser pensadas mais como operadores que orientam as práticas, tanto "ali", naqueles supracitados locais, como alhures. São elas a “azaração", a "sarração", o "baco" e o "relacionamento" (os termos para nomeá-las foram tomados do próprio discurso nativo).

A “azaração" atravessa todos aqueles espaços, ainda que, no espaço comum das ruas, apareça de forma quase autônoma. Nessa ordem, o sentido corporal mais utilizado é a visão. As sutis trocas de olhares podem sinalizar os desejos e caracterizam os atos da "pegação". Uma discursividade gestual que pode dar passagem a "sarrações", "bacos" ou "relacionamentos".

As "sarrações", por sua vez, não se restringem a espaços como o do Congado. Elas ocorrerão onde multidões de aglomeram e podem ser caracterizadas pelas transgressões das regras hegemônicas de proxemia (Alferes, 1987), como uma espécie de invasão dos limites de contato corporais, comuns nas relações cotidianas nãosexuais - sobretudo na percepção que os outros (os que não estão envolvidos na "sarração") têm das interações que estão observando. Assim, também estarão presentes nos ônibus e em trens superlotados, nos bailes de carnaval, nos namoros de "pé de muro" dos casais etc.

A busca e o encontro de "relacionamentos" não se restringem aos lugares normalmente concebidos como "de família”, próprios para os encontros e enlaces que tendem a se tornar duradouros, lugares que prezam pelas regras hegemônicas do decoro, onde se alinham os terreiros de candomblé, as festas em casas de amigos, os grupos gays, bares e boates etc. Não obstante onde o relacionamento opere, é a possibilidade da palavra que faz com que outras interações sexuais ("azaração”, "sarros” e "bacos”) caminhem para o namoro ou amizade, cingindo compromissos que atravessam aquele momento. Palavra que também pode surgir em espaços "orgiásticos" como um "banheirão da Central”, um clube de sexo etc.

O "baco", uma forma condensada de bacanal, se refere ao que em geral se concebe como práticas sexuais (felação, sexo anal etc.), em que duas ou mais pessoas estão envolvidas. Vale salientar que, no sistema erótico, há a primazia de práticas marginalizadas pelos discursos normativos da sexualidade (religiosos, médico etc.). Além de estar presente, entre outros lugares, nos "quartos escuros" das boates ou nos "swings" do funk (local nos bailes, em geral um aposento mais escuro, onde há brincadeira de troca de casais e interações eróticas que vão da "sarração" ao "baco"), essa ordem invade a santidade dos lares, "as quatro paredes" que consagram as interações sexuais. Também nesse âmbito, as interações duais, preconizadas pelos outros sistemas de entendimento da vida sexual, são subvertidas com a entrada (real, virtual ou imaginária) de terceiros, o que, muitas vezes, ajuda a manter (ou incrementar) a excitação sexual dos casais. Isso pode se dar na privacidade, na rememoração de outras interações com outras pessoas ou na imaginação de possibilidades, mas também pode invadir o casal, quando ambos incrementam suas excitações ao observar outros casais em "sarros" ou "transas" - também no real ou no virtual, quando vêem sites eróticos na Internet, assistem a filmes pornôs etc.

Volto a enfatizar que, na verdade, as práticas sexuais estarão, em maior ou menor grau, atravessadas pelas quatro ordens, ainda que, em determinados locais, nas suas próprias constitui- 
ções sociossexuais, uma ou outra prevaleça. É importante que eu deixe claro, até para evitar um certo obscurantismo heterossexista e moralizante, que as quatro ordens também orientarão - ainda que com matizes diferentes e marcadas por um certo reprodutivismo - a organização da heterossexualidade.

Não estou querendo dizer que encontrei a sexualidade liberta das regras e acordos, em seu estado in natura. Pelo contrário, como bem mostrou Parker (1991), não devemos pensar o erótico como "a essência do sexual”, livre da cultura: gostos e prazeres, práticas e representações eróticas são, também, construções culturais e variam de uma sociedade para outra.

\section{A sexualidade infantil e intergeracional}

Dando seguimento a esse processo de conceituação do sexual como construção cultural, quero resgatar o surgimento das interações e prazeres sexuais entre as crianças. Muitos dos jovens com quem tenho conversado, talvez por medo da perversão e/ou culpa, não conseguem pensar como sexuais suas primeiras experiências eróticas - aquelas realizadas na infância, quando experimentavam com seus pares o potencial de prazer guardados em seus corpos. Mas, quando se vêem diante de um interlocutor acolhedor e que tenta estar isento de valoração sobre as práticas, conseguem descrever as interações que viveram, ainda que posterguem discursivamente o que chamam de "suas verdadeiras iniciações sexuais" para a “juventude" - em geral, por volta dos 14 anos.

Essa ocultação traz, consigo, uma outra: as relações entre gerações. E faço eco e tento responder ao questionamento lançado por Fry (1983:48): "seria interessante saber quantos meninos encontram sua sexualidade, não através de prostitutas ou 'Donas Frau', como, por exemplo, em Amar, verbo intransitivo, de Mário de Andrade, mas sim através de homens mais velhos".

Os jovens com quem tenho conversado relatam que tiveram suas primeiras relações eróticas entre 5 e 14 anos, sendo as experiências de sexo penetrativo realizadas, em geral, com homens (crianças, jovens ou adultos) mais velhos (chegando a diferença de idade entre parceiros a entorno de dez anos). Esse é um roteiro de relacionamentos que se perpetua até a idade adulta (por volta dos 30 anos), com grande tendência a se inverter (busca por homens mais jovens). Eles justificam o que consideram um "padrão normal de iniciação sexual" dizendo que "é natural o mais velho ensinar ao mais novo e inexperiente as artes do sexo". Contudo, o que se vê é que, para além desse processo, acresce-se, na explicação para organização dessas parcerias, em nível discursivo e prático, um valor econômico: a possibilidade de ganhos e facilidades no consumo de bens e serviços, que suas condições financeiras não permitem, por meio do relacionamento sexual com um homem mais velho.

O que era "capital sexual" vai se transformando, ou se acrescentando de capital sócioeconômico (a citada estabilidade sócio-financeira). Vale ressaltar que, nesse processo, algo soa, usando uma expressão do discurso marxista, como "fetichismo da mercadoria" (Marx, 1987), jovem. Uma questão que se coloca para futuras investigações é em que medida as condições de classe e a própria precarização do mercado de trabalho (para os jovens e suas famílias) intervêm na constituição desse padrão de parceria intergeracional.

Continuando a deixar em suspensão as situações que efetivamente ferem o Estatuto da Criança e do Adolescente (Brasil, 1990) - e que, definitivamente, pelos relatos que tenho recolhido, não são numericamente desconsideráveis e precisam ser realmente encaradas para que se possa formular respostas mais apropriadas para violência e abusos sexuais -, o padrão que tenho visto se constituir é o de crianças se relacionando entre si; crianças se relacionando com adolescentes/jovens, numa cadeia sexual que chega até a adultez.

\section{Saúde sexual: a infantilização da epidemia de HIV/AIDS}

Pensando nas implicações dessa cadeia para a saúde sexual de crianças e jovens, quero retomar para discussão os dados epidemiológicos que apontam para uma juvenilização da epidemia de HIV/AIDS (Rios et al., 2002). Conforme Barreira (2002), os dados epidemiológicos sobre homens com práticas homossexuais revelam que há uma tendência discreta de decréscimo do número de novos casos de AIDS para os homens com 24 anos ou mais, e uma tendência de crescimento entre os menores de 24 anos. Ele sugere que possa estar havendo um recrudescimento da epidemia entre homens com práticas homossexuais às custas dos indivíduos mais jovens.

Recentemente, justificando sua campanha de carnaval de 2003, direcionada ao público feminino entre 13 e 19 anos, o Ministério da Saúde (MS) divulgou em nota oficial: "em 2000, foram 191 casos em meninas de 13 a 19 anos contra 151 casos em rapazes da mesma idade. Em 
2001, foram notificados 152 casos de AIDS em adolescentes do sexo feminino, contra $91 \mathrm{em}$ adolescentes homens. Entre os jovens de até 24 anos, esta relação homem/mulher já está igual, tendendo para as mulheres superarem os homens também" (Brasil, 2003).

No resumo de uma pesquisa citada na mesma nota, vale enfatizar que foi encontrado, à semelhança dos meus achados com meninos, que "as meninas, geralmente, têm suas primeiras relações sexuais com parceiros mais velhos que elas" (Brasil, 2003). Ainda conforme a nota do MS, o "total de casos notificados em jovens de 13 a 24 anos de idade desde 1980: [é de] 29.613 casos". Desses, 19.229 são meninos e 10.384, meninas.

Ora, diante dos padrões de relacionamento e interações eróticas que tenho levantado e dos dados epidemiológicos que transcrevi acima, e quando penso na juvenilização que se processa tanto entre heterossexuais como entre homossexuais, poderia ir mais adiante e questionar: o quão próximos estamos de uma infantilização da epidemia do HIV, fora da transmissão vertical?

Lembro que as notificações, com as quais o Programa Nacional de DST/AIDS constrói os dados epidemiológicos, se referem aos casos de AIDS e não aos de soropositividade. Também lembro do período assintomático, entre a infecção propriamente dita e a manifestação da síndrome, que pode variar de 5 a 10 anos. Ora, se os dados revelam um avanço da epidemia para meninos e meninas entre 13 e 19 anos, os jovens devem estar se infectando entre 7 e 14 anos - o que reflete a idade das experiências sexuais dos homens com que tenho conversado.

Por outro lado, em relação aos casos de AIDS em indivíduos menores de 13 anos de idade, segundo categoria de exposição hierarquizada (total de 1980 a 2002), conforme o Boletim Epidemiológico - AIDS (Brasil, 2002), 7,3\% são classificados na categoria de exposição ignorada, chegando, em 2000, a computar 11,4\%. Questiono: até que ponto o moralismo sexual e a crença de que crianças não se relacionam sexualmente estão impedindo que se classifiquem os casos acima apresentados, concebidos como de exposição ignorada, como sendo realmente causados por transmissão por via sexual? Também questiono, pelo mesmo processo assinalado, até que ponto se tem interrompido (ou se quer cogitado) investigações das causas mortes em vítimas de doenças oportunistas, ligadas à imunodeficiência, em crianças e adolescentes - que não nasceram de mães soropositivas ou que não receberam transfusão de sangue -, causando uma subnotificação de diagnósticos de casos de AIDS? Lembro que foram as representações sociossexuais na linha destas, que ocultavam as práticas vividas na cotidianidade, as responsáveis pela demora em respostas e o reforço de certos percursos da epidemia (Treichler, 1999).

\section{Considerações finais}

Após pouco mais de 20 anos de epidemia, o fenômeno do sexo desprotegido continua um desafio para pesquisas e ações, constantemente nos fazendo refletir sobre a eficácia das ações preventivas realizadas. Acredito que, além de pensar nos paradigmas usados para as ações (Parker, 2000), devemos, cada vez mais, em nossas pesquisas e ações educativas, incorporar o que comumente "colocamos debaixo do tapete": encarar o erótico - que, em detrimento da "ordem médica" e de outras normas de sexualidade hegemônicas, constituem padrões específicos de se comportar sexualmente (Parker, 1991). O sexual, enquanto construção social, é muito mais que a satisfação de necessidades básicas ou a ferramenta para a reprodução de espécimes e manutenção do exército de mão-de-obra; ele está sobretudo relacionado, como bem mostram as interações sexuais das crianças, com a busca pela socialidade e pela diversão.

Como tentei mostrar, seja nos circuitos homoeróticos, seja nas interações heterossexuais, a "azaração", a “sarração", o "baco" e o "relacionamento" estarão vez ou outra operando. Eles precisam ser encarados nas pesquisas e ações não como supostos desvios das normas, mas como possibilidades utilizadas e consentidas pelos envolvidos, para a obtenção do prazer.

É certo que precisamos incorporar, nas ações educativas, informações sobre os riscos que algumas práticas eróticas possam ter para a saúde (como, por exemplo, as recorrentes cenas do compartilhamento de preservativos em sexo grupal que, como observei, ocorrem no Aterro) ou que contrariam princípios éticos como o da autonomia (as interações sexuais intergeracionais envolvendo crianças e adultos, por exemplo). Mas creio que essa incorporação não deva se dar com base em perspectivas moralizantes e/ou autoritárias, que, conforme Paiva (2002), Parker (2000), Almeida et al. (2002), mais afastam os sujeitos da reflexão sobre as informações que estão sendo oferecidas, do que possibilitam a formação de sujeitos sexuais (Paiva, 2000) - que, entre outras atribuições, possui a capacidade de negociação e es- 
colha em relação às normas sexuais vigentes, assumindo as implicações de seus atos, ainda que resultem em, por exemplo, uma infecção por uma doença sexualmente transmissível.

Do mesmo modo - e saindo da perspectiva repressora vigente, que nega, interdita e pune as interações sexuais infantis -, a meu ver, também é com o objetivo de formar sujeitos sexuais que se deveria pautar as ações com as crianças. Isso sem desconsiderar as questões éticas e legais ligadas à autonomia e às posições de poder dos envolvidos nas interações sexuais, e que caracterizam as relações sexuais entre adultos e crianças como abuso e violência (Oliveira, 2003; Petchesky, 1999; Rios, 2002a).

Diante das evidências sobre as redes sexuais que atravessam gerações (e que, volto a enfatizar, não necessariamente envolvem violação de direitos) e que podem servir de trajeto para infecções como o HIV, penso que informações e insumos precisam ser desenvolvidos também para as crianças. Evidências mostram que a subjetivação (sexual) é um processo que se inicia antes mesmo do nascimento, pois envolve as fantasias da comunidade que irá recebê-la (Rodulfo, 1990). Assim, acredito ser possível e necessário falar e aprender com as crianças sobre o sexual; fomentar, desde muito cedo, a autonomia sexual, o direito a escolhas e as suas implicações para suas vidas e qualidades de vida; possibilitar o diálogo aberto, sem repressão ou culpa sobre o prazer sexual - o que inclusive possibilitaria uma maior eficácia no combate ao abuso e à violência sexuais.

Contudo, questiono a eficácia em constituir plenamente as crianças como sujeitos sexuais. Enquanto processo, a subjetivação sexual envolve amadurecimentos individuais (em que se alinham aspectos biológicos, instrucionais, econômicos etc.), ainda que parte deles seja possibilitada pela coletividade que a cerca. $O$ cabedal de pesquisas que possuímos me parece insuficiente para se estabelecer em que momento uma criança terá atingido o ponto em que sua auto- nomia sexual lhe permitirá optar conscientemente por seus atos (sexuais). Lembro ainda que, sobretudo as crianças mais novas, estão na ordem do lúdico, do imaginário; brincando de ser gente, experienciando as diferentes potencialidades de seus corpos e de seus mundos (Rodulfo, 1990).

Esses argumentos vão ao encontro da própria Convenção sobre os Direitos da Criança, ratificada pelo Brasil em 1990. A convenção reconhece a criança como verdadeiro sujeito de direito, ainda que se encontre em condições peculiares de desenvolvimento. Por isso, os Estados signatários devem garantir-lhes o direito à proteção especial (Piovesan \& Pirotta, 2003). Ora, ante a juvenilização e infatilização da epidemia de HIV/AIDS que se processa, a identificação do comprometimento no que se refere às crianças - por peculiares condições de desenvolvimento - fazerem uso da prevenção, e também por acreditar ser ineficaz - e mesmo danoso para o desenvolvimento psicossexual perspectivas autoritárias que enfatizam a abstinência sexual como única resposta para lhes promover saúde sexual, quero argumentar que devemos aumentar os nossos clamores aos Estados signatários da Convenção por substanciais investimentos para a descoberta de uma vacina contra o HIV. Só assim poderemos prevenir uma tragédia ainda mais grave do que a que temos hoje.

Por fim, e retomando a temática que me conduziu por boa parte deste artigo, o erótico, enfatizo que, para termos mais sucesso em nossas abordagens de educação em saúde e de advocacy por uma sociedade mais justa e eqüitativa, precisamos conceitualizar - nas ações e nas pesquisas - os desejos, os prazeres e vivências (homo)eróticas, tanto como construções socioculturais, quanto como bens afirmativos: o direito universal de usufruir plenamente do próprio corpo e dos prazeres que este pode oferecer (Petchesky, 1999). 


\section{Agradecimentos}

Quero registrar o meu especial agradecimento aos jovens que compartilharam comigo suas experiências sexuais. Também sou grato a Lady Selma Albernaz, que me instigou a escrever este artigo; a Vagner de Almeida, com quem colaboro na condução do projeto Juventude e Diversidade Sexual (ABIA/PNDST/AIDS); a Ivia Maksud e a Magaly Pazello, pelas leituras e sugestões que ajudaram a enriquecer e tornar mais claro este artigo; e a Leandro Bastos, coetnógrafo em muitas das passagens deste trabalho, além de companheiro de todas as horas.

\section{Referências}

ALFERES, V., 1987. O corpo: Regularidades discursivas, representações e patologias. Revista Crítica de Ciências Sociais, 23:211-219. 4 Abril 2003 <http://www.fpce.uc.pt/nucleos/niips/i_pub/val _pub/corpo.htm>.

ALMEIDA, V.; RIOS, L. F. \& PARKER, R., 2002. Ritos e Ditos de Jovens Gays. Rio de Janeiro: Associação Brasileira Interdisciplinar de AIDS.

BARREIRA, D., 2002. Tendências Epidemiológicas. In: Novos Desafios da Prevenção da Epidemia pelo HIVIAIDS Junto aos Homens que Fazem Sexo com Homens (Brasil, org.), pp. 24-25, Brasília: Ministério da Saúde.

BRASIL, 1990. Estatuto da Criança e do Adolescente. 15 Setembro $2003<$ http://www.planalto.gov.br/ ccivil_03/Leis/L8069.htm>.

BRASIL, 2002. Boletim Epidemiológico - AIDS. Ano XV, no 1. Brasília. Coordenação Nacional de DST/ AIDS.

BRASIL, 2003. Nota sobre a Campanha de Carnaval. 27 Março 2003 <http://www.aids.gov.br/final/imprensal/carnaval_2003_porque.htm>.

CONSELHO FEDERAL DE MEDICINA, 1996. Normas de pesquisa envolvendo seres humanos. Resolução CNS 196/96. Bioética, 4(2 Suplemento):15-25.

FRY, P., 1983. Léonie, Pombinha, Amaro e Aleixo: Prostituição, homossexualidade e raça em dois romances naturalistas. In: Caminhos Cruzados (C. Vogt, org.), pp. 33-52, São Paulo: Brasiliense.

MARX, K., 1987. O Capital - Livro 1. São Paulo: Bertrand Brasil.
OLIVEIRA, A. (org.), 2003. Abuso Sexual de Crianças e Adolescentes: Desafios na Qualificação Profissional. Rio de Janeiro: Nova Pesquisa.

PAIVA, V., 2000. Fazendo Arte com a Camisinha: Sexualidades Jovens em Tempos de AIDS. São Paulo: Summus.

PAIVA, V., 2002. Sem mágicas soluções: A prevenção ao HIV e à AIDS como um processo de "emancipação psicossocial”. In: Prevenção à AIDS: Limites e possibilidades na terceira década (R. Parker e V. Terto Jr.), pp. 20-27, Rio de Janeiro: Associação Brasileira Interdisciplinar de AIDS.

PARKER, R., 1991. Corpos, Prazeres e Paixões: A Cultura Sexual no Brasil Contemporâneo. São Paulo: Best Seller.

PARKER, R., 2000. Na Contramão da AIDS: Sexualidade, Intervenção, Política. Rio de Janeiro: Associação Brasileira Interdisciplinar de AIDS/São Paulo: Editora 34.

PARKER, R., 2002. Abaixo do Equador. Rio de Janeiro: Record.

PETCHESKY, R., 1999. Direitos sexuais: Um novo conceito na prática política internacional. In: Sexualidades pelo Avesso: Direitos, Identidades e Poder (M. R. Barbosa \& R. Parker, org.), pp. 15-38, São Paulo: Editora 34.

PIOVESAN, F. \& PIROTTA, W., 2003. Os direitos humanos das crianças e dos adolescentes no direito internacional e no direito interno. In: Temas de Direitos Humanos (F. Piovesan, org.), pp. 237-276, São Paulo: Max Limond. 
RIOS, L., 1997. Loce Loce, Metá Rê-Lê! Homossexualidade e Transe(tividade) de Gênero no Candomblé de Nação. Dissertação de Mestrado, Recife: Departamento de Ciências Sociais, Universidade Federal de Pernambuco.

RIOS, L., 2001. Parcerias Sexuais e Práticas Eróticas entre Jovens HSH Adeptos do Candomblé: Um Estudo Etnográfico entre Comunidades-Terreiros Cariocas. Projeto apresentado ao IV Programa de Metodologia em Gênero, Sexualidade e Saúde Reprodutiva. Campinas: Núcleo de Estudos Populacionais, Universidade Estadual de Campinas.

RIOS, L., 2002a. Quando o assunto é cultura sexual: um "olhar sobre a mídia". In: Olhar sobre a Mídia (Comissão de Cidadania e Reprodução, org.), pp. 169-146, Belo Horizonte: Mazza.

RIOS, L., 2002b. Comportamento Sexual e Saúde: Reflexões sobre a Prevenção do HIVIAIDS entre Jovens HSH no Brasil. Santiago: Facultad Latinoamericana de Ciencias Sociales. (mimeo.)

RIOS, L.; PIMENTA, C.; BRITO, I.; TERTO Jr., V. \& PARKER, R., 2002. Rumo à adultez: Oportunidades e barreiras para a saúde sexual dos jovens brasileiros. Cadernos CEDES, 22:45-62.
RODULFO, R., 1990. O Brincar e o Significante. Porto Alegre: Artes Médicas.

RUBIN, G., 1998. Thinking sex: Notes for a radical theory of the politics of sexuality. In: Social Perspectives in Lesbian and Gay Studies: A Reader (P. Nardir \& B. Schneider, ed.), pp. 100-133, London: Routledge.

SAHLINS, M., 1990. Ilhas de História. Rio de Janeiro: Zahar.

SIMON, W. \& GAGNON, J., 1999. Sexual scripts. In: Culture, Society and Sexuality: A Reader (R. Parker \& P. Aggleton, ed.), pp. 29-38, London: UCL Press.

TERTO Jr., V., 1989. No Escurinho do Cinema...: Socialidade Orgiástica nas Tardes Cariocas. Dissertação de Mestrado, Rio de Janeiro: Pontifícia Universidade Católica do Rio de Janeiro.

TREICHLER, P., 1999. AIDS, homophobia, and biomedical discourse: An epidemic of signification. In: Culture, Society and Sexuality: A Reader (R. Parker \& P. Aggleton, ed.), pp. 357-386, London: UCL Press.

Submetido em 30 de maio de 2003

Versão final reapresentada em 3 de setembro de 2003 Aprovado em 16 de setembro de 2003 